\title{
A new Starlight Reserve for the central South Island of New Zealand
}

\author{
John Hearnshaw \\ Dept. of Physics and Astronomy \\ University of Canterbury, Christchurch, New Zealand \\ email: john.hearnshaw@canterbury.ac.nz
}

\begin{abstract}
The Aoraki Mackenzie International Dark Sky Reserve is a new reserve created in 2012 by the International Dark-Sky Association in the central South Island of New Zealand, and covers over 4300 square kilometres around Mt John University Observatory. It is the first such reserve to be recognized at gold tier level and is the largest dark sky reserve in the world. Astro-tourism in the new reserve will be a prominent activity in the coming years.
\end{abstract}

Keywords. Dark sky reserve, combatting light pollution, astro-tourism

\section{Overview}

We recently made a proposal for a new Dark Sky Reserve in the centre of the South Island of New Zealand, to be known as the Aoraki Mackenzie International Dark Sky Reserve. The area includes Mt John University Observatory and all of Aoraki/Mt Cook National Park and covers 4367 square kilometres. There are three small centres of population in the Reserve, with a total population of about 1500 people. Most of this large area has had light pollution controlled by a lighting ordinance since 1981 (possibly the first in the southern hemisphere), so as to limit light pollution through filtering, shielding and the time of operation of outdoor illumination. The National Park also has lighting controls in place. The sky is exceptionally dark (averaging about $21.7 \mathrm{~V}$ magnitudes per square arcsec in the core regions of the reserve) and the air is very clear and unpolluted, making it an ideal place for stargazing. A number of astro-tourism companies are now thriving in this region, and over 20,000 visitors annually, coming from all over the world, are benefitting from guided night sky tours.

The reserve was recognized in April 2012 by the International Dark-Sky Association in Tucson AZ and was granted gold tier status, the first in the world at gold tier level and just the third dark sky reserve to be recognized by IDA. It is also the first reserve to be declared in the southern hemisphere and the largest reserve area. Full details of the application document to IDA can be viewed on-line (Austin et al. 2012). A management board is now being established for the reserve, so as to monitor compliance with the lighting ordinance, to recommend improvements to outdoor lighting and to organize activities in the reserve to promote astro-tourism. Our plans are to stay at the forefront of the fast-growing international dark sky reserve movement, and to set a standard for dark skies and light pollution controls for others to follow.

\section{Reference}

Austin, M. E., Hearnshaw, J. B., Butler, S., \& Loveridge, A. 2012, An Application to the International Dark-Sky Association for a Starlight Reserve in the Aoraki/Mt Cook National Park and the Mackenzie Basin of the central South Island of New Zealand, pp xii +167 , http://www.saps.canterbury.ac.nz/starlight/ 